\title{
Sentidos e significados no processo de aprendizagem no ensino superior a distância: a atuação do tutor presencial
}

Senses and meanings in the learning process in distance college education: the presential tutor's performance

Sentidos y significados em el proceso de aprendizaje em educación superior a distancia: el desempeño del tutor presencial

Recebido: 11/02/2021 | Revisado: 20/02/2021 | Aceito: 23/02/2021 | Publicado: 28/02/2021

\author{
Aline Fernanda Soeiro \\ ORCID: https://orcid.org/0000-0002-6137-8184 \\ Rede Municipal de Educação, Brasil \\ E-mail: alinefsoeiro@gmail.com \\ Andréa Forgiarini Cecchin \\ ORCID: https://orcid.org/0000-0001-6945-9731 \\ Universidade Federal de Santa Maria, Brasil \\ E-mail: andrea.cecchin@ufsm.br \\ Vanessa dos Santos Nogueira \\ ORCID: https://orcid.org/0000-0002-5070-3607 \\ Faculdade SOBRESP, Brasil \\ E-mail: snvanessa@gmail.com
}

\begin{abstract}
Resumo
O presente estudo busca compreender as possíveis implicações da atuação do tutor presencial nos processos de ensino-aprendizagem discentes, considerando os polos de abrangência do Curso de Pedagogia, entre os anos de 2017 a 2019, no âmbito da Universidade Aberta do Brasil (UAB). Essa pesquisa foi realizada através do estudo desenvolvido no Programa de Mestrado Profissional em Políticas Públicas e Gestão Educacional da Universidade Federal de Santa Maria. Inicialmente, realizou-se a sistematização das normativas legais, procurando entender as principais funções do tutor presencial e como elas vinham sendo desenvolvidas no Curso de Pedagogia UAB/UFSM. Buscou-se perceber, a partir do ponto de vista dos sujeitos da pesquisa como as atribuições desses tutores podem influenciar os processos de ensino-aprendizagem dos estudantes. A investigação, de natureza aplicada, ancorou-se em uma abordagem qualitativa, entrelaçando a consulta a documentos e dados empíricos à escuta dos sujeitos envolvidos diretamente com o curso. A coleta de dados envolveu entrevistas semiestruturadas com tutores presenciais e uma escuta dialógica com estudantes de dois polos atendidos pelo curso. Os dados foram analisados a partir da Análise Textual Discursiva, da qual emergiram três categorias: Percepção dos sujeitos acerca das atividades desenvolvidas pelo tutor presencial; Relações/interações entre os sujeitos implicados nos processos de ensino-aprendizagem em EAD, e influência do tutor presencial nos processos de ensino-aprendizagem. Deste cenário de pesquisa, resultou como produto a criação de um ambiente colaborativo de aprendizagem entre os tutores presenciais do curso, utilizando-se da ferramenta eletrônica Padlet.
\end{abstract}

Palavras-chave: Educação a distância; Tutor presencial; Universidade Aberta do Brasil; Ensino-aprendizagem.

\begin{abstract}
This study seeks to understand the possible implications of the presence of the presential tutor in the teaching-learning processes of students, considering the poles of scope of the Pedagogy Course, between the years 2017 to 2019 , within the scope of the Open University of Brazil (UAB). This research was carried out through the study developed in the Professional Master's Program in Public Policies and Educational Management at the Federal University of Santa Maria. First, we sought to know the roles of presential tutor in the Pedagogy course.We sought to perceive, from the point of view of the research subjects, how the attributions of these tutors can influence the students' teaching-learning processes. The investigation, of an applied nature, was anchored in a qualitative approach, interweaving the consultation with documents and empirical data to listen to the subjects directly involved with the course. Data collection involved semi-structured interviews with presentials tutors and a dialogical listening with students from two centers attended by the course. The data were analyzed based on the Discursive Textual Analysis, from which three categories emerged: Perception of the subjects about the activities developed by the presential tutor; Relations/interactions between the subjects involved in the teaching-learning processes in distance learning, and influence of the presential tutor in the teaching-learning processes. From this research scenario, the product resulted in
\end{abstract}


the creation of a collaborative learning environment among the presentials tutors of the course, using the electronic tool Padlet.

Keywords: Distance education; Presencial tutor; Open University of Brazil; Teaching-learning.

\section{Resumen}

Este estudio busca comprender las posibles implicaciones de la presencia del tutor presencial en los procesos de enseñanza-aprendizaje de los estudiantes, considerando los polos de alcance del Curso de Pedagogía, entre los años 2017 a 2019, en el ámbito de la Universidad Abierta de Brasil (UAB). Esta investigación se realizó através del estudio desarrollado en el Programa de Maestría Profesional en Políticas Públicas y Gestión Educativa de la Universidad Federal de Santa María. Inicialmente se sistematizó la normativa legal, buscando entender las principales funciones del tutor presencial. Se buscó percibir, desde el punto de vista de los sujetos de investigación, cómo las atribuciones de estos tutores pueden influir en los procesos de enseñanza-aprendizaje de los estudiantes. La investigación, de carácter aplicado, se ancló en un enfoque cualitativo, entretejiendo la consulta con documentos y datos empíricos. La recogida de datos implicó entrevistas semiestructuradas con tutores presenciales y una escucha dialógica con alumnos de dos centros a los que asistió el curso. Los datos fueron analizados con base en el Análisis Textual Discursivo, del cual emergieron tres categorías: Percepción de los sujetos sobre las actividades desarrolladas por el tutor presencial; Relaciones/interacciones entre los sujetos implicados en los procesos de enseñanza-aprendizaje en la educación a distancia, e influencia del tutor presencial en los procesos de enseñanza-aprendizaje. A partir de este escenario de investigación, el producto resultó en la creación de un ambiente de aprendizaje colaborativo entre los tutores presenciales, utilizando el Padlet.

Palabras clave: Educación a distância; Tutor presencial; Universidad Abierta de Brasil; Enseñanza-aprendizaje.

\section{Introdução}

O presente texto busca compreender os sentidos e significados da intervenção do tutor presencial nos polos de abrangência do Curso de Pedagogia a distância da UFSM, no âmbito da Universidade Aberta do Brasil, e as possíveis implicações nos processos de ensino-aprendizagem discentes. A pesquisa foi desenvolvida no Programa de Mestrado Profissional em Políticas Públicas e Gestão Educacional, da Universidade Federal de Santa Maria (UFSM).

O aporte teórico que fundamentou a pesquisa e a base para análise do corpus foi organizado a partir das contribuições e reflexões de autores que se dedicam a temática da Educação a Distância (EAD). Entre eles: Mill (2016), Behar (2013), Carvalho (2009), Peters (2004), Moore e Kearsley (2013), Nogueira (2014), entre outros, e das Políticas Públicas que regulamentam a modalidade de ensino a distância. No que tange ao referencial metodológico, tomou por base os estudos de Lakatos e Marconi (2008), Flick (2009) e Gil (2010), compreendendo o contexto em que se deu a pesquisa e, na sequência, as fontes, os instrumentos de coleta de informações e as estratégias para análise de dados.

Compreende-se que a Educação a Distância é uma modalidade de ensino a qual discentes e docentes estão separados, geograficamente, e através do uso das Tecnologias Digitais de Informação e Comunicação promovem uma mediação didáticopedagógica dos processos de ensino-aprendizagem. Neste estudo, busca-se apresentar os movimentos constitutivos das atividades de tutoria desenvolvidos pelos tutores presenciais do Curso de Pedagogia EAD/UFSM. Para isto, considera os indicativos das Políticas Públicas acerca da função e atuação do tutor e seus desdobramentos a partir da intervenção do tutor nos processos de ensino-aprendizagem dos estudantes.

\section{Percurso Metodológico}

Para dar conta do proposto, optou-se por realizar uma pesquisa de abordagem qualitativa que, segundo Flick (2009, p. 21), "pode ser definida como uma metodologia que produz dados a partir de observações extraídas diretamente do estudo de pessoas, lugares ou processos com os quais o pesquisador procura estabelecer uma interação direta para compreender os fenômenos estudados". Ou seja, esta abordagem privilegia as falas dos sujeitos pesquisados e procura desenvolver teorias empiricamente fundamentadas, além de trazer contribuições importantes no campo da pesquisa social, tendo em vista seu caráter investigativo e descritivo.

No período do desenvolvimento deste estudo, entre os anos de 2017 e 2019, o curso de Pedagogia UAB/UFSM 
atendia 20 polos, distribuídos em diferentes municípios do estado do Rio Grande do Sul. Contava com a seguinte equipe: 36 professores, 65 tutores a distância e 22 tutores presenciais. Havia, ainda, dois tutores presenciais designados especificamente para realizar o atendimento educacional especializado, para alunos com deficiência.

Ao considerar este universo de pesquisa tão amplo, optou-se por delimitá-lo, restringindo-o a cinco polos. Definiu-se como critério para seleção dos sujeitos o tempo de atuação como tutor presencial no curso: participaram os cincos tutores com maior tempo de vínculo com o curso. Deste modo, definiu-se como sujeitos desta pesquisa: cinco tutoras presenciais do Curso de Pedagogia UAB/UFSM, e duas turmas de estudantes atendidas por estes tutores. Considerando que as tutoras com maior tempo de vínculo com o curso - principais sujeitos do estudo - eram do gênero feminino, o texto irá referir-se aos tutores presenciais sempre no feminino.

Os instrumentos de coleta de dados foram constituídos a partir de entrevistas semiestruturadas com tutoras presenciais do curso de Pedagogia UAB/UFSM. Organizou-se também um momento de escuta com duas turmas de estudantes por elas atendidas. Ressalta-se que a escolha da entrevista como um dos instrumentos de coleta se deu, por ser uma das formas onde há uma maior interação entre o pesquisador e os sujeitos da pesquisa, possibilitando a organização de um ambiente de diálogo que objetiva a busca de informações pertinentes à temática e ao que se pretende compreender. Segundo Pereira et. al. (2018), entre as vantagens das entrevistas como instrumento de coleta podemos citar a possibilidade de obter dados referentes a diferentes aspectos envolvidos na pesquisa; coletar dados sobre o comportamento dos entrevistados; classificação dos dados coletados; facilidade no registro dos dados (o entrevistado não precisa ser alfabetizado); a entrevista oferece a possibilidade de esclarecimentos caso o pesquisador tenha alguma dúvida acerca de alguma resposta. Além disto, nas entrevistas é possível observar expressões corporais e a entonação da voz do entrevistado.

A partir de um primeiro olhar sobre as entrevistas, surgiu a necessidade de ampliar os dados para compreensão do cenário de pesquisa. Diante disto, foi organizado encontro com duas turmas de estudantes, de dois polos distintos, para ouvilos, através de um processo que denominamos de escuta reflexiva.

A escuta reflexiva realizada com estes discentes partiu do recorte do método denominado sessão reflexiva, que definido por Ibiapina (2008) pode ser entendido como algo que vai além da observação, pois o pesquisador busca seus dados através de longas conversas em pequenos grupos. Ao corroborar com esta definição, Santos (2011) complementa que esta é "[...] um espaço de reflexão colaborativa sobre as práticas de ensino e aprendizagem, buscando descrevê-las, informá-las, confrontá-las e, quiçá, reconstruí-las”. Assim, optou-se por usar uma nomenclatura baseada na palavra escuta e não sessão, pois o momento de encontro com os estudantes foi baseado, principalmente neste movimento de "dar voz", ou seja, de deixar os sujeitos implicados na pesquisa falarem. Nestes momentos de escuta reflexiva, em uma reunião que durava aproximadamente duas horas, era dada ao grupo oportunidade de manifestarem suas impressões sobre a intervenção da tutora presencial a partir de um questionamento inicial.

Dessa forma, apesar do foco inicial da pesquisa contemplar as tutoras presenciais, a escuta reflexiva com os discentes apresentou-se como um fator importante para compreender de modo mais amplo a atuação das tutoras presenciais nos processos de ensino-aprendizagem.

A Análise Textual Discursiva, proposta por Moraes e Galiazzi (2007), foi a metodologia escolhida para análise do corpus, pois esse recurso aprofunda a compreensão dos fenômenos sobre os quais se propõe a investigar, e não apenas testa hipóteses para comprová-las ou refutá-las ao final da pesquisa. Entende-se que numa perspectiva qualitativa, esse método pode contribuir para a compreensão do processo em análise, à medida que tem por objetivo apresentar o surgimento de novas compreensões realizadas através dos textos, neste caso, as entrevistas e diálogos transcritos a partir das escutas significativas. 


\section{Algumas Reflexões Sobre os Resultados Encontrados}

Ao submeter os dados da pesquisa a esse procedimento de análise, três grandes categorias surgiram como significativas para o estudo: a percepção que os sujeitos têm acerca do trabalho da tutora presencial; as relações/interações entre os sujeitos implicados nos processos de ensino-aprendizagem em EAD e a influência da tutora presencial nos processos de ensino- aprendizagem.

\subsection{As atividades desenvolvidas pela tutoria presencial}

Conforme a organização do sistema da Universidade Aberta do Brasil, projeto que estrutura o curso de Pedagogia da UAB/UFSM, o tutor presencial possui atribuições definidas por uma legislação específica. As ações envolvem desde uma rotina, tempo para o atendimento dos estudantes, até concepções na realização das atividades que qualificam e organizam suas atribuições.

Dentre esta rotina, ao ouvir as tutoras presenciais, sujeitos da pesquisa, percebe-se que elas desconheciam a legislação sobre tutoria e sobre o sistema da UAB. A fala dessa Tutora Presencial 1 (TP1) demostram essa questão:

Ah, a legislação nem toda, não tenho conhecimento, mas eu tenho ciência das atribuições do tutor nas atividades do polo, isso eu tenho por que foi nas orientações, na página do curso, e foi passada pela coordenadora. (TP1)

As tutoras presenciais não compreendiam suas atribuições descritas na legislação. Para esses sujeitos, a linguagem era confusa e não especificava objetivamente o que deveria fazer o tutor presencial. Assim, muitas vezes, pautavam seu trabalho no que lhes era repassado pela coordenação do curso, em algumas formações que participaram, e nas informações nos sites de pesquisa que tinham acesso, como o da própria UAB.

Ao mesmo tempo em que expressavam desconhecimento sobre as políticas que regulamentavam sua função, não demonstravam interesse em buscar informações sobre o desenvolvimento do seu trabalho em outros espaços, tais como: Plataforma CAPES, SISUAB, aplicativo de pagamento das bolsas, assim como comunidades de tutores nas mídias sociais, nas quais poderiam encontrar pessoas com objetivos e assuntos em comum. Das cinco entrevistadas, apenas uma sinalizou conhecimento sobre um destes recursos, o aplicativo que demonstrava o controle do pagamento de cotas aos bolsistas do Sistema UAB.

Não podemos deixar de problematizar se isto não se relaciona com a forma como essas tutoras encaravam essa atividade: apesar da compreensão da relevância da sua atuação, não era esta atividade que definia sua carreira, como exemplificam as falas que seguem:

Eu trabalho durante o dia todo na escola, é puxado, nossa rotina em sala de aula não é fácil, mas é o que nos dáo maior sustento financeiro, a bolsa recebi pela tutoria vem complementar a renda. (TP2)

A tutoria tem que ser no turno da noite, porque durante o dia eu trabalho no município como professora concursada 40 horas, então este é único horário que posso estar lá, e também facilita para os alunos porque a maioria trabalha durante o dia. (TP4)

Sendo assim, fica evidenciado nestas falas que a tutoria servia como um complemento financeiro, ao mesmo tempo em que, deixava a carga horária semanal de trabalho das tutoras numa média de 60 horas: 40 horas em seus trabalhos regulares, mais 20 horas de tutoria. Ao visualizar este cenário, é difícil compreender como essas pessoas poderiam pensar em formação 
continuada ou qualificação para uma atividade desvalorizada financeiramente. Cabe lembrar que, na época da pesquisa as bolsas da UAB já não sofriam reajuste há quase dez anos e o curso de Pedagogia passava por um redimensionamento em função de cortes orçamentários.

O descontentamento e o desconhecimento sobre a remuneração recebida e sobre o trabalho desenvolvido também aparece nas falas da tutoras, ao relatarem:

Eu não tenho muito conhecimento em relação até a questão financeira das bolsas, que como eu já venho de uma caminhada de educação a distância né, de tutoria, a bolsa, na época a gente, era 600 na educação especial, era 2010, 600 reais a bolsa, aí em seguida já passou para 675 reais, a figura do tutor ela é permanente, mas a questão da bolsa ela ficou praticamente estagnada nesta questão da valorização salarial também. Realmente teve só este acréscimo e não mudou mais. (TP4)

Acho muito pouco o que ganhamos, pelo o que fizemos no curso, mas não sei dizer por que é somente isso, mas é algo a se mobilizarmos para questionar. (TP3)

Este fator é algo que precisa ser levado em consideração, pois se pode definir a bolsa recebida pelo tutor como um valor que está defasado. Passados 12 anos desde a implementação do Sistema UAB, os valores das bolsas foram reajustas apenas uma vez, em 2009.

Ao pensarem sobre suas rotinas de trabalho, o modo de organização dos tempos e espaços das atividades, os horários que costumavam atender aos estudantes e que atividades desenvolviam, algumas tutoras relatam que:

Eu trabalho no turno noturno, porque a maioria dos alunos trabalham no diurno, então não teria o porquê vir no diurno, então a gente tá no polo disponível a partir das 18 horas, nos dias que eu estou aqui a gente organiza grupo de estudos, esses grupos de estudo que a gente faz, eu sento com a turma, a gente abre disciplina por disciplina, lê, conversa sobre a atividade que tá sendo solicitada. (TP1)

Grupos de estudos, seminários, algumas vezes seminários acadêmicos, encontros aqui no polo e também avaliações presenciais, são atividades que a gente mais realiza e quando tem aulas presenciais. (TP2)

Essas práticas correspondiam ao compromisso de estar no polo três vezes por semana, prioritariamente no turno da noite, pelo fato dos estudantes trabalharem durante o dia. Além disso, elas tinham o compromisso de estar presentes em todas as atividades presenciais, como provas, reuniões com a coordenação e demais programações que ocorriam durante o semestre letivo, de acordo com cada polo de apoio presencial.

Com isso, nota-se que o processo de ensino-aprendizagem está ligado diretamente ao fazer docente que a tutora presencial realizava nos polos de apoio. Através da rotina de atividades estabelecidas, as tutoras conseguiam estruturar mecanismos nos quais os estudantes desenvolviam melhores condições de aprendizagem significativas. Nos encontros de escuta reflexiva com a Turma de Discentes 1 (TD1), algumas falas aparecem para corroborar isto:

[..] termos um tutor presencial no polo, é o que faz a diferença, porque junto com nós (sic) ela consegue organizar os grupos de estudo e auxiliar no que precisamos. (TD1)

[...] eu sei que nosso curso é a distância, mas faz muita falta ter aquele contato com alguém, então o tutor presencial 
é a pessoa que vai poder esclarecer nossas dúvidas e ajudar nas dificuldades. (TD1)

...ela nos dá um gás toda vez que viemos ao polo, e isso faz a diferença porque conseguimos estar melhores para aprender. (TD2)

Portanto, percebe-se que a presença física deste sujeito poderia realmente significar a diferença entre o insucesso e o êxito acadêmico dos estudantes do curso de Pedagogia UAB/UFSM, pois, além de ser a figura que representa o docente, realizava a mediação no processo de ensino-aprendizagem.

\subsection{A interação nos processos de ensino-aprendizagem}

Segundo Piaget (1976), as interações são indispensáveis para que ocorra assimilação e a acomodação, ocasionando assim a internalização e, como consequência, o processo de adaptação, entendido como crucial para uma aprendizagem significativa. Esses processos ocorrem independentemente da modalidade educacional, ou seja, também na educação a distância.

A partir destas considerações, destaca-se que as relações/interações no curso de Pedagogia UAB/UFSM se davam através do contato, sejam virtuais ou presenciais, entre os sujeitos implicados, os quais, de forma geral, diziam respeito aos docentes, tutores a distância, tutores presenciais, estudantes e coordenação do curso. Sobre o modo como os profissionais da educação precisam se relacionar e interagir, diariamente, com pessoas, de universos tão distintos, Mill (2014) evidencia que:

É preciso ressaltar que essas interações diferem das interações encontradas em outras profissões; raros profissionais enfrentam situações diárias em que têm que interagir, ao mesmo tempo, com tantos indivíduos com necessidades tão variadas. Mesmo assim, a interação com os alunos é apenas uma das várias ações docentes (Mill, 2014, p. 90).

Sem dúvidas, a prática docente é uma das atividades que mais possui relações e interações ao mesmo tempo, pois estar em uma turma já demanda a necessidade de saber como agir frente à heterogeneidade dos estudantes, e também, com a equipe gestora das instituições. As relações são responsáveis por grande parte dos processos que ocorrem, sejam eles presenciais ou virtuais.

Através das entrevistas semiestruturadas, ao perguntar especificamente a cada tutora como elas viam sua relação com a coordenação do curso, ficou evidente que havia uma interação muito boa com a equipe gestora. Com isso, foi possível verificar que, de forma geral, todas possuíam uma boa relação com a coordenação do curso e as interações, geralmente, aconteciam de forma harmônica, mantendo uma linha de comunicação ativa e contínua.

Entretanto, ao se tratar das relações entre as tutoras presenciais e os tutores a distância, percebe-se que estas se estabeleciam de uma forma diferente, conforme ilustram as falas a seguir:

Assim, eu não costumo ter muita comunicação com os tutores a distância, às vezes, a gente manda mensagem e entra em contato e nem recebe o retorno que a gente gostaria, e tem vezes que a mensagem direta para o professor tem mais efeito. (TP1)

Olha, eu mandei acho que duas mensagens para dois tutores a distância, nunca tive resposta, então não costumo me relacionar com eles.

[...] acredito que o problema principal é nós não nos conhecermos, porque o tutor a distância que costuma vir nos dias de prova, ao falar com ele pelo ambiente, é mais tranquilo, porque já o conhecemos e isso melhora a comunicação. (TP5) 
É possível observar que a relação das tutoras presenciais com os tutores a distância, ainda apresentava dificuldades. Acredita-se que, apesar destes sujeitos estarem vinculados a um curso a distância, a presença física fazia toda a diferença. Inclusive para comunicações pertinentes ao andamento do curso, além da comunicação virtual realizada em prol das significações referentes aos processos de aprendizagem dos estudantes, reforçando assim a construção do conhecimento real e duradouro.

Ao se relacionar o tutor presencial e o tutor a distância, se percebeu que a interação entre eles era quase mínima. Entretanto, quando se direcionava a escuta para a relação com os professores do curso, o nível de interações se modificava, como indica a fala que segue:

Minha relação é boa, posso dizer que é melhor do que com a do tutor a distância, pois os professores me respondem de imediato e sempre que necessário entram em contato comigo, mas penso que, ainda esta relação acontece mais pelo ambiente de aprendizagem. (TP1)

Deste modo, as interações existentes nas relações entre as tutoras presenciais e os docentes do curso, mostravam-se satisfatórias, ocorrendo, em sua maioria, dentro do ambiente virtual de ensino-aprendizagem. Estas aproximações serviam basicamente para resolver questões pontuais sobre o conteúdo da disciplina, ficando evidente que não correspondiam a uma relação mais estreita entre estes pares. Este fator não parecia contribuir de forma relevante para a aprendizagem dos estudantes, pois se acredita que se houvesse maior reciprocidade e comunicação efetiva, isso teria uma maior visibilidade no processo de aprendizagem.

Portanto, nas diversas relações analisadas, se conseguiu perceber um cenário onde as interações poderiam ser mais eficazes e com qualidade. Entende-se que isto se deve ao fato da comunicação virtual ser empobrecida, sem muitas intervenções e discussões entre os pares envolvidos nos processos de ensino-aprendizagem a distância. Para corroborar o que se está trazendo, contrapõem-se aqui algumas falas dos discentes nos momentos de escuta reflexiva:

Eu prefiro me comunicar com o tutor presencial do que com o tutor a distância, porque às vezes eu envio mensagem para ele e nada de responder. (TD1)

Eu até tenho facilidade em me comunicar pelo ambiente com os professores, tutores e tudo mais, mas acontece que a demora com que te respondem faz tu pensar que a pergunta nem era importante, e isso nos desestimula a perguntar de novo. (TP2)

Prefiro recorrer sempre ao tutor presencial primeiro, já que ele me ajuda a encontrar os meios certos para tirar minhas dúvidas, ou até mesmo como me ajudar a fazer as perguntas para tutores e professores pelo ambiente. (TD2)

Diante disso, não há como se definir que a falha na comunicação era responsabilidade de apenas uma das partes envolvidas neste contexto, pois se sabe que estar inserido nos meios digitais, em busca de formação e conhecimento, requer intencionalidade específica e, sobretudo, iniciativa em prol de reflexões críticas e participativas.

\subsection{O tutor presencial e os processos de ensino-aprendizagem}

Ao considerar que os modelos mentais e vivências dos sujeitos da pesquisa são permeados por práticas de ensino presencial, os processos de ensino-aprendizagem mediados pela internet representam um novo cenário. Estes processos vivenciados anteriormente fazem com que os acadêmicos busquem a representação de professor presencial, alguém que possa 
representar para esses sujeitos o modelo de aprendizagem que conhecia até então. Desta forma, fica evidenciado nas falas dos tutores presenciais que foram sujeitos na pesquisa, quando relatam sobre sua influência nos processos de aprendizagem dos discentes:

Eu acredito que faz total diferença na aprendizagem, porque o tutor presencial é de suma importância para a aprendizagem do aluno, até mesmo como eu já disse, no método que uso de ficar incentivando para não desistir, estudar mais e ter mais momentos que tu incentive ele para que faça a leitura para compreender as atividades. (TP1)

Às vezes a figura do tutor presencial é muito forte para o aluno, porque ele tendo esse vínculo, ele vem falar comigo antes de falar com o próprio professor EAD... Eles tem confiança, acredito que seja essa a palavra. (TP4)

Essa percepção implícita de estimular e dar suporte aos anseios que faziam parte da rotina dos estudantes apareceu de forma marcante tanto nas falas das tutoras, como nas dos estudantes ao relatar a disponibilidade das tutoras em atendê-los. O recorte a seguir representa esse sentimento de gratidão dos estudantes:

A tutora é quem nos ajuda, e nos motiva a não desistir, ela ajuda a organizar nossos estudos, manda mensagem, auxilia avisando o que falta (TD1)

A tutora muitas vezes me ajudou a não desistir, escutou meus problemas particulares, me motivo a continuar sempre.

Eu me sinto ligada ao curso através da tutora, nunca estudei a distância, e ela que me ajuda, principalmente a não desistir. (TD4)

Um dos aspectos que podem influenciar os processos de aprendizagem é a organização do tempo. Para estudar a distância é preciso que se crie hábitos diários, de forma a aperfeiçoar sua rotina acadêmica, harmonizando-a com sua vida pessoal, já que se sabe que estes estudantes geralmente conciliavam estudo com trabalho:

[...] tive que organizar a vida de estudos dos alunos aqui no polo, muitos não tinham o hábito diário de estudar, juntos organizamos cronogramas e dividimos tarefas e leituras contemplando todos os dias da semana. (TP2)

Sem a tutora presencial eu já teria desistido, ela me motivou a continuar apesar de tudo o que passei e das várias vezes que pensei em largar tudo, porque estudar, cuidar casa, trabalhar fora, não é fácil. (TD2)

Dessa forma, a atuação das tutoras permeava também o auxílio de orientar, explicar, e até mesmo ajudar os estudantes a organizarem rotinas fixas de estudo, considerando suas realidades, articulando a vida acadêmica com a profissional.

Vale ressaltar que a aprendizagem na UAB/EAD envolve o uso intenso das tecnologias digitais de informação e comunicação e, nesse cenário o papel do tutor presencial contribui para que os estudantes se aproximem desse novo modo de aprender. $\mathrm{O}$ aluno na EAD precisa aprender a manusear diferentes ferramentas tecnológicas para que possa dar conta de seu processo de aprendizagem, pode-se perceber essa necessidade nas falas a seguir:

[...] a gente sabe que o tutor presencial tem a função de ambientalizar o aluno, ajudar no ambiente de aprendizagem, ajudar na parte estrutural dos trabalhos e no computador com as ferramentas que tem ali [...]. (TP1) 
Tem muitos alunos que ao iniciarem a graduação não sabiam nem mexer em um computador, e quem deu todo este suporte foi eu, desde o uso para a pesquisa, até as ferramentas do nosso ambiente de aprendizagem, que é o Moodle. (TP3)

Apesar de todas as contribuições e esforços das partes envolvidas no processo de aprendizagem na EAD, o estudo demonstrou que a fluência tecnológica e questões relacionadas ao conteúdo era uma demanda constante no durante o curso. No entanto, é importante ressaltar que, de acordo com a legislação que ampara a atuação do tutor presencial, Guia de Tutores UAB (2009) e Referenciais de Qualidade para a Educação a Distância (2007), dentre suas funções este deverá auxiliar as dúvidas referentes aos conteúdos disciplinares.

Entretanto, observou-se através da escuta reflexiva, que o auxílio realizado ao estudante pelas tutoras presenciais contemplava as atribuições descritas na legislação. O suporte presencial potencializa os processos de ensino-aprendizagem e agregava também o apoio e suporte ao uso das ferramentas tecnológicas e comunicação pelas redes sociais.

\section{Considerações Finais}

Ao nos remetermos às atribuições desenvolvidas nos polos de apoio pelas tutoras presenciais, pode-se destacar que suas rotinas eram alteradas de acordo as demandas de cada contexto. As tutoras presenciais realizavam suas atividades de acordo com a indicação das Políticas Públicas, buscando o engajamento e permanência dos estudantes.

O curso de Pedagogia UAB/UFSM mobiliza relações/interações dinâmicas. Percebe-se que a EAD representa uma mudança de cenário entre os participantes. A alteração dos modos de comunicação e aprendizagem exigem o desenvolvimento de novas habilidades e competências.

Considera-se que a presença física do tutor presencial é uma referência importante, principalmente no início do curso ao considerar que esse é um período de transição entre as modalidades de aprendizagem. Ao visualizar todo este cenário, podese indicar que o tutor presencial tem uma função de intervenção que favorece os processos de ensino-aprendizagem. Entretanto, diferente do que se imaginava no início da investigação, sua atuação está mais diretamente vinculada às questões que dizem respeito à motivação para aprendizagem, à organização para os estudos e não necessariamente às dúvidas de conteúdo. Santo (2016) realizou um estudo exploratório sobre a polidocência na educação a distância e um dos seus achados de pesquisa corrobora o encontrado aqui: “que os princípios que deveriam nortear a prática de mediação tutorial na EaD se relacionam com o estabelecimento do vínculo afetivo-pedagógico com o estudante” (p. 92). Ora, é possível pensar que o estabelecimento de uma relação segura, de uma referência afetiva é um ponto importante para dar início a aprendizagens duradouras. Assim, a existência do tutor presencial como sendo o "porto seguro", aquele que muitas vezes conforta, auxilia, apoia, pode ser um fator determinante não só para evitar a evasão como também para garantir os índices de permanência nos cursos.

As análises do estudo apontam para a necessidade de qualificação para que o tutor presencial conheça as políticas públicas que organizam o trabalho e os processos de ensino-aprendizagem na EAD. Ao pensar nessas questões, o produto resultante da pesquisa foi a criação de um mural virtual como recurso formativo para estes tutores. Entre as opções existentes, optou-se pelo Padlet.

O Padlet pode ser entendido como um recurso para a elaboração de um sistema baseado em um mural online, que tem como característica ser virtual e gratuito na sua versão básica. É uma ferramenta colaborativa que pode ser compartilhada com os demais usuários, que podem visualizar ou editar. Ele apresenta características que permitem interação dos sujeitos, difundindo ideias, cultura, democratizando as informações e tornando possível a aprendizagem em rede. A intenção principal deste produto foi proporcionar momentos de compartilhamento de saberes e aprendizagens, sem a necessidade de encontros 
presenciais, através de diferentes recursos e mídias de forma virtual.

Através desta iniciativa de produto, buscou-se proporcionar interatividade e um momento de troca de saberes pertinentes à prática docente dos tutores presenciais dentro do sistema UAB/UFSM, promovendo colaboração e permitindo reflexões sobre suas atribuições.

O estudo realizado proporcionou uma compreensão do trabalho do tutor presencial apresentando alternativas para qualificar sua atuação. A pesquisa ofereceu indicativos para o desenvolvimento de novos estudos, que busquem o entrelaçamento com as práticas pedagógicas do tutor a distância frente ao balizamento legal, a partir das políticas públicas que organizam o sistema da UAB.

\section{Referências}

Behar, P. A. (2013). Competências em educação a distância. Penso.

Brasil (2015). Conselho Nacional de Educação. Diretrizes para Educação a Distância na Educação Superior. http://portalmec.gov.br/index.php?option=com_docman\&view=download\&alias=16558-texto-referencia-educacao-distancia-ead-pdf\&category_slug=outubro2014-pdf\&Itemid=30192.

Brasil (2005). Decreto n. 5.622, de 19 de dezembro de 2005. Brasília, DF. \http://portal.mec.gov.br/seed/arquivos/pdf/ dec_5622.pdf.

Brasil (2006). Decreto $\mathrm{n}^{\mathrm{o}}$. 5.800, de 08 de junho de 2006. Universidade Aberta do Brasil. http://uab.capes.gov.br/index .php?option=com_content \&view $=$ section\&id=4\&Itemid=22

Brasil (2007). Ministério da Educação e Cultura - MEC. Secretaria de Educação a Distância. Referenciais de qualidade para cursos a distância. Brasília, DF Ministério da Educação. http://portal.mec.gov.br/seed/arquivos/pdf/legislacao/refead1.pdf.

Carvalho, A. B. (2009). A educação a distância e a formação de professores na perspectiva dos estudos culturais. 220f. Tese (Doutorado em Educação) Universidade Federal da Paraíba, João Pessoa.

Carvalho, A. B. (2008). Tutoria: concepções e práticas na educação a distância. Anais do 32 ENANPAD.

Flick, U. (2009). Introdução à Pesquisa Qualitativa. (3a ed.), ArtMed.

Fujita, O. M. (2010). Educação à Distância, currículo e competência: uma proposta de formação on-line para a gestão empresarial. 284p. Tese (Doutorado em Educação) - Universidade de São Paulo, São Paulo.

Gil, A. C. (2010). Como elaborar projetos de pesquisa. (5a ed.), Atlas.

Mill, D. R. S. (2016). Das inovações tecnológicas às inovações pedagógicas: considerações sobre o uso de tecnologias na Educação a Distância. Mill, D. (2016). Educação a Distância: cenários, dilemas e perspectivas. Revista de Educação Pública, 25(59/2), 432-454. https://doi.org/10.29286/rep.v25i59/2.3821

Moore, M. \& Kearsley, G. (2013). Educação a distância: sistema de aprendizagem on-line. (3a ed.), Cengage Learning.

Moore, M. \& Kearsley, G. (2010). Educação a distância: uma visão integrada. Cengape Learning.

Moraes, R., \& Galiazzi, M. (2007). Análise textual discursiva. Editora Unijuí.

Pereira A. S. et al. (2018). Metodologia da pesquisa científica. UFSM. https://repositorio.ufsm.br/bitstream/handle/1/15824/Lic_Computacao_MetodologiaPesquisa-Cientifica.pdf?sequence $=1$.

Peters, O. (2004). A Educação a Distância em Transição: tendências e desafios. Unisinos.

Santo, E. do E. (2016). Ensinar e aprender na Educação a Distância: um estudo exploratório na perspectiva das práticas tutoriais. Research, Society and Development, 3(2), 92-114. https://doi.org/10.17648/rsd-v3i2.16.

Santos, C. L. B. dos. (2011). A sessão reflexiva na formação de cinco professores de inglês da escola pública: que gênero discursivo é esse? Anais do Encontro Estadual de Didática e Prática de Ensino, Goiânia, GO. http://www.ceped.ueg.br/anais/ivedipe/pdfs/lingua_literatura_estrangeira/co/CO\%20404-894-1SM.pdf 